American management in the hope that more of them will take this view and will subscribe to the slogan "There is profit in prevention.' It contains twelve sections dealing separately with a wide variety of subjects such as industrial skin diseases, dust hazards, metal poisoning, toxic gases and vapours, solvents, fatigue, monotony and noise, the control of airborne industrial hazards, safety administration, personal protective equipment, mechanical and plant safety. Classifications of potential hazards according to the main industries and occupations are given. It is well indexed and illustrated with photographs, which give some good examples of safety devices.

The questions are answered simply and briefly, sometimes too briefly, but a short list of books and articles for further reading is given at the end of each section. It will be a useful book for all concerned with the health and safety of workers, particularly industrial management and safety officers; but it does not give all the detail necessary for the industrial medical officer in Great Britain who will find it very difficult to obtain the literature suggested for further reading as it is almost entirely American.

R. S. F. S.

\section{FACTORY ORDERS: 1944 EDITION}

Regulations and Orders under the Factories Act 1937 and certain other Acts

(H.M. Stationery Office, London. 1944. Pp. 388. 5s.)

The number of regulations and orders issued in connexion with health, welfare and safety in factories in recent years has become so great that only with the greatest difficulty can any person keep up to date. And so this bound volume, produced by the Ministry of Labour and National Service, is most welcome. It should be on the book-shelves of every industrial medical officer and Examining Surgeon in the country.

There is no doubt that His Majesty's Stationery Office are first-class publishers. The lay-out of this volume is good, the type is clear and of sufficient size to be read easily, and the price is most reasonable. It is a pity that only paper covers are provided; they cannot stand up to the continuous usage that the book must demand. One more point. Is it possible for the Stationery Office, now the producer of so many best-sellers, to open branches in cities other than London, Manchester, Edinburgh, Cardiff and Belfast? Why are there none in Birmingham, Liverpool, Sheffield, Leeds, Bristol, Newcastle and Glasgow?

D. S.

\section{DISPERSAL}

An inquiry made by the National Council of Social Service

(Oxford University Press, London. 1944. Pp. 96. $3 s .6 d$.)

In winter 1944, when housing is as urgent a problem as the need for aircraft was in 1940 , it is timely to have the result of an inquiry into the problem of dispersal. A royal proclamation in the reign of Queen Elizabeth called upon 'all maner of persons . . . to desist and forbeare from any newe buyldings of any house or tenement within three miles from any of the Gates of the sayd Citie of London.' Since then the spread has continued and was particularly marked between the two wars. The same had occurred in the other large cities, though less severely. This inquiry deals with the dispersal of clerical and administrative staffs belonging to government departments, banks, insurance companies and similar organizations. The desirability of dispersal for the common good is obvious; but for the staffs such problems as housing, entertainment facilities, educational and health services have to be considered. For the company the main problem is of satisfactory liaison between evacuated staff and the central office. From the point of view of doctors perhaps the most interesting part of the book is the discussion of health services. It correctly points out that the standard of general practitioners broadly speaking is higher in the provincial town than in the suburbs of a large city, but that consultants are not of such high standard and are less accessible. The existence of a well-managed hospital with a supply of private beds at reasonable cost is probably the matter of greatest importance to the group of persons under consideration. This inquiry is an able dissertation on a subject of great interest at the present time, and is worthy of study by all interested in the problem. One fears, however, that despite the facts presented here, there is grave risk that the great cities will continue to sprawl over the countryside. $\quad$ K. M. A. P.

HEALTH AND SOCIAL WELFARE, 1944-1945

Advisory Editor, Lord Horder, G.C.V.O., M.D., F.R.C.P.

(Todd Publishing Co., Ltd., London. 1944. Pp. 336.

$$
\text { 21s.) }
$$

This volume is the latest addition to the publisher's series of annual reference books, and is especially directed to all those who are concerned with health education and social welfare. "It has been the aim of the Advisory Editor, Lord Horder, to present all points of view in the form of articles by experienced writers and to give factual and statistical information in as concise a form as possible for the many thousands of people engaged in this field of work.'

Among notable articles are 'Public Health To-day and To-morrow' by Sir Arthur MacNalty, 'Planning for Health' by Dr. Edith Summerskill, M.P., 'The B.M.A and the Medical Services' by Dr. Charles Hill, 'State Medicine' by Dr. Somerville Hastings, 'Progress in Public Health, 1844-1944' by M. Caston, the 'School Medical Service' by Dr. J. E. A. Underwood, while Mr. R. R. Hyde writes on "The Development and Scope of Industrial Welfare Work.' Later sections contain valuable summaries of Government Committee Reports (e.g. Beveridge, Tomlinson, Norwood, Fleming, etc.), followed by a section on health legislation and a series of valuable articles on health and welfare overseas in which Dr. Joan McMichael writes on 'Soviet Health and Social Welfare Services,' and Martin Götz gives us a clear survey of the 'Scope of U.N.N.R.A.' Official directories of the various ministries and official bodies connected with health are given and there are useful statements on policy and work by the ministries and by representative organizations including the B.M.A., Medical Research Council, Industrial Health Research Board, Miners' Welfare Commission, National Institute of Industrial Psychology and other bodies. This section gives the concise information required by a doctor or health worker who wishes to learn or to explain what the societies and organizations are doing. The final reference section gives a comprehensive and up-to-date list of books, periodicals and films dealing with health and social welfare. The book is enlivened by some excellent cartoons by 'Sallon' of the Minister of Health, Dr. Charles Hill, Sir William Beveridge and others, and is well printed and bound.

J. G. B. 